\title{
Retinal detachment in albinism
}

\author{
Ahmad M Mansour ${ }^{1,2}$ \\ Jay Chhablani ${ }^{3}$ \\ J Fernando Arevalo 4,5 \\ Lihteh $\mathrm{Wu}^{6}$ \\ Ravi Sharma ${ }^{3}$ \\ Suthasinee Sinawat ${ }^{7}$ \\ Tharikarn Sujirakul ${ }^{8}$ \\ Alexandre Assi ${ }^{9}$ \\ Wandsy MVélez-Vázquez ${ }^{10}$ \\ Mohamad A Mansour ${ }^{1}$ \\ Ozcan Kayikcioglu" \\ Cem Kucukerdonmez ${ }^{12}$ \\ Ali Kal ${ }^{13}$ \\ 'Department of Ophthalmology, \\ American University of Beirut, \\ Beirut, Lebanon; ${ }^{2}$ Department \\ of Ophthalmology, Rafic Hariri \\ University Hospital, Beirut, Lebanon; \\ ${ }^{3}$ L.V. Prasad Eye Institute, Banjara \\ Hills, Hyderabad, India; ${ }^{4}$ Department \\ of Ophthalmology, Johns Hopkins \\ Bayview Medical Center, Baltimore, \\ MD, USA; ${ }^{5}$ Wilmer Eye Institute, \\ Johns Hopkins University School \\ of Medicine, Baltimore, MD, USA; \\ ${ }^{6}$ Asociados de Macula Vitreo y Retina \\ de Costa Rica, San José, Costa Rica; \\ ${ }^{7}$ Department of Ophthalmology, \\ Srinagarind Hospital, Khon Kaen \\ University, Khon Kaen, Thailand; \\ ${ }^{8}$ Department of Ophthalmology, \\ Ramathibodi Hospital, Mahidol \\ University, Bangkok, Thailand; ${ }^{9}$ Beirut \\ Eye and Ear Specialty Hospital, \\ Beirut, Lebanon; ${ }^{10}$ Retina Associates, \\ Guaynabo, Puerto Rico; "Celal Bayar \\ University, Manisa, Turkey; ${ }^{12}$ Ekol Eye \\ Hospital, Izmir, Turkey; ${ }^{13}$ Department \\ of Ophthalmology, Baskent University, \\ Konya, Turkey
}

Correspondence: Ahmad M Mansour Department of Ophthalmology, American University of Beirut, POB I I 3-6044, Beirut, Lebanon Tel +96I 3377633

Email ammansourmd@gmail.com
This article was published in the following Dove Press journal:

Clinical Ophthalmology

Purpose: To report the visual and anatomic outcomes of albino retinal detachment (ARD) repair.

Methods: Collaborative retrospective analysis of ARD. Outcome measures were number of surgical interventions, final retinal reattachment, and best corrected visual acuity (BCVA) at last follow-up.

Results: Seventeen eyes of 16 patients ( 12 males; mean age $=37.8$ years) had the following complications at presentation: macula off (14), total (7) or inferior detachment (5), proliferative vitreoretinopathy (5), detectable break (16), lattice (5), horseshoe tears (9), and giant tear or dialysis (4). Mean number of interventions was 1.8 (range $=1-5$ ) and included cryopexy (15) with scleral buckle (11), and/or vitrectomy (8). Mean initial BCVA was counting finger (CF) $1 \mathrm{~m}$ and at last follow-up (mean 77 months) CF4m with mean improvement of 4.5 lines (early treatment diabetic retinopathy study) $(P=0.05)$. Intraoperative choroidal hemorrhage occurred in three eyes. The retina was finally attached in 14 eyes, with residual inferior detachment in three eyes with silicone oil in situ. Silicone oil was kept in six of seven eyes because of residual inferior detachment (3) and removal of silicone oil, which led to redetachment (1) or fear of redetachment (2).

Conclusion: Repair of ARD may require several interventions, with the need to keep silicone oil in several cases due to nystagmus and reduced melanin pigment.

Keywords: cryopexy, foveal hypoplasia, nystagmus, retinal detachment, scleral buckle, silicone oil, vitrectomy

\section{Introduction}

Albinism is a diverse group of genetic disorders of melanin biosynthesis that include $\mathrm{X}$-linked ocular albinism and various types of oculocutaneous albinism. Tyrosinase is a major enzyme involved in melanin production which is deficient in albinism to varying degrees. Retinal detachment in albinism is rarely discussed in the literature. ${ }^{1-4}$ Several problems arise in such conditions: inadequate visualization of retinal breaks from loss of contrast between retina and choroid, ${ }^{1}$ the inability for the laser to induce a good chorioretinal adhesion, and fast nystagmus that aggravates vitreous currents. Our study aims to further extend prior observations ${ }^{1-4}$ and identify retinal detachment outcomes in a large original case series.

\section{Methods}

This is a collaborative retrospective study of a consecutive case series of albino retinal detachment (ARD). The study received institutional review board approval (Rafic Hariri University Hospital). Patient consent to review their medical records was not required as only de-identified information was used. All patients had iris transillumination defects, reduced vision, nystagmus, retinal hypopigmentation, and foveal hypoplasia. Variables included detachment location, number of tears or presence of dialysis, presence of proliferative vitreoretinopathy (PVR), and details of surgery 
(scleral buckle [SB] or pars plana vitrectomy [PPV]) with intraoperative and postoperative complications. Snellen best corrected visual acuity (BCVA) was converted to logMar for statistical analyses. Wilcoxon signed-rank test for two paired samples was carried out to analyze the change in visual acuity. PVR was classified according to the updated Retina Society Classification. ${ }^{5}$

\section{Results}

Seventeen eyes of 16 patients (12 males and four females; eight Caucasian, six Indian, two Asian) were included (Table 1). Mean age was 37.8 years (range $=12-61$ ). The site involved included 12 left eyes, four right eyes, and one undetermined. The macula was detached in 14 eyes at presentation. The detachment was total or near total in seven eyes, inferior in location in five eyes, superior in two eyes, superior and temporal in one eye, superotemporal in one eye, and nasal in one eye. PVR was present in five eyes, with Grade A in two eyes, Grade B in one eye, and Grade CA in two eyes with long-standing detachment. Preoperatively or intra-operatively, the break could be localized in 16 eyes, while the retinal break could not be found in one eye. History of blunt trauma was elicited in two cases. Pseudophakia was already present in three eyes. Lattice was detected in five eyes (lattice was a bystander in two eyes and the cause of retinal detachment (RD) in three eyes: one horseshoe tear at the edge of the lattice and atrophic holes inside the lattice in two eyes). Nine eyes had horseshoe tears (two eyes having two tears and seven eyes having one tear). A giant tear was found in two eyes and 2-3 clock hour dialysis in two eyes.

Laser retinopexy (using a slit lamp argon laser delivery system) as a primary therapy was tried in two patients,

Table I Clinical characteristics of retinal detachment in albinism case series

\begin{tabular}{|c|c|c|c|c|c|c|c|c|}
\hline Patient & $\mathrm{I}$ & 2 & 3 & 4 & 5 & 6 & 7 & 8 \\
\hline Age (years) & 38 & 42 & 13 & 18 & 12 & 29 & 51 & 29 \\
\hline Sex & $\mathrm{F}$ & $M$ & $M$ & $\mathrm{~F}$ & $M$ & $M$ & M & $M$ \\
\hline Race & 1 & 1 & I & 1 & 1 & 1 & $A$ & $C$ \\
\hline OD/OS & OS & OS & OS & OS & OS & OD & OS & OS \\
\hline Initial vision & $20 / 317$ & CFI5 cm & $20 / 100$ & CF2m & $20 / 500$ & $20 / 500$ & $20 / 200$ & $20 / 200$ \\
\hline RD location & Superior & Inferior & Inferior & Total & Total & Total & $\begin{array}{l}\text { Superior }+ \\
\text { temporal }\end{array}$ & Nasal \\
\hline Macula off & Off & Off & Off & Off & Off & Off & Off & On \\
\hline Tear number and location & $\begin{array}{l}\text { Superior } \\
\text { round holes; } \\
\text { lattice }\end{array}$ & HST superotemporal & $\begin{array}{l}\text { Dialysis } \\
\text { infero- } \\
\text { temporal }\end{array}$ & $\begin{array}{l}\text { HST } \\
\text { temporal; } \\
\text { lattice }\end{array}$ & $\begin{array}{l}\text { HST } \\
\text { superior }\end{array}$ & HST superior & Can't find & $\begin{array}{l}\text { HST } \\
\text { nasal }\end{array}$ \\
\hline PVR grade at presentation & No & No & A & No & No & No & B & No \\
\hline Nystagmus severity & No & No & No & No & No & No & No & Mild \\
\hline High myopia ( $<-6$ diopters) & No & Yes & No & No & No & No & No & No \\
\hline Initial surgery & SB & PPV & SB & SB & SB & SB & PPV & SB \\
\hline $\begin{array}{l}\text { Total number of eye } \\
\text { surgeries }\end{array}$ & 1 & 3 & 1 & 1 & I & 4 & $\mathrm{I}$ & 1 \\
\hline SB & Yes & No & Yes & Yes & Yes & Yes & No & Yes \\
\hline PPV & No & Yes & No & No & No & No & PPV & No \\
\hline $\mathrm{C} 3 \mathrm{~F} 8$ & No & No & No & No & No & No & No & No \\
\hline Silicone oil & No & Yes & No & No & No & No & No & No \\
\hline Endolaser & No & Yes & No & No & No & No & Yes & No \\
\hline Cryopexy & Yes & Yes & Yes & Yes & Yes & Yes & No & Yes \\
\hline Follow-up & $3 \mathrm{~m}$ & $3 y$ & $\mathrm{I} \mathrm{m}$ & $10 \mathrm{~m}$ & $\mathrm{I} \mathrm{m}$ & $12 \mathrm{~m}$ & $12 \mathrm{~m}$ & $12 \mathrm{~m}$ \\
\hline Final vision & $20 / 200$ & $20 / 200$ & $20 / 80$ & $20 / 120$ & $20 / 159$ & $20 / 30$ & $20 / 200$ & $20 / 200$ \\
\hline Additional surgeries & No & $\begin{array}{l}\text { SO exchange, endolaser, } \\
\text { cryopexy, retinotomy } \\
\text { ( } 2 \mathrm{~m} \text { after first surgery); } \\
\text { SO exchange and } \\
\text { endolaser } \\
\text { ( } 18 \mathrm{~m} \text { after first } \\
\text { surgery) }\end{array}$ & No & No & No & $\begin{array}{l}\text { PPV, endolaser, SO } \\
\text { injection I month } \\
\text { after first surgery; } \\
\text { SO removal ( } 6 \mathrm{~m} \\
\text { after first surgery); } \\
\text { trabeculectomy ( } 36 \mathrm{~m} \\
\text { after first surgery) }\end{array}$ & Retinotomy & No \\
\hline
\end{tabular}

Abbreviations: RD, retinal detachment; PVR, proliferative vitreoretinopathy; m, months; y, years; HST, horseshoe tear; PPV, pars plana vitrectomy; SB, scleral buckle; LP, light perception; HM, hand motion; CF, counting finger; phaco, phacoemulsification; SO, silicone oil; OD, right eye; OS, left eye; M, male; F, female; I, Indian; C, Caucasian; A, Asian; ND, not determined; PCO, posterior capsular opacification. 
but failed. Endolaser (green laser) was performed in a total of five eyes (none had previous slit lamp laser retinopexy), but failed completely in three eyes and succeeded partially in two eyes. Cryopexy was done in 15 eyes. The other treatments were pneumoretinopexy using C3F8 (one eye), SB (11 eyes), vitrectomy with C3F8 gas tamponade (two eyes), and vitrectomy with silicone oil (five eyes). Intraoperative complications occurred in three eyes: non-expulsive diffuse choroidal hemorrhage after cryopexy in one eye and intraretinal and subretinal hemorrhage from a high-energy argon endolaser that was transient resolving 1-3 weeks postoperatively in two eyes.

The mean follow-up was 77 months (range $=1-540$; median $=12$ months). Among the vitrectomized eyes, three eyes had recurrence at 1-2 months with oil in situ, resulting in localized flat stable inferior detachment. The rest of the eyes had attached retinas at the last follow-up. Epiretinal membrane (ERM) was prominent in four eyes. Mean initial BCVA was CF1m median CF2m range (20/40-LP). Best postop BCVA was $5 \mathrm{~m}$ (median $2 \mathrm{~m}$ ). Mean at last follow-up was CF4m median CF2m range (20/30-LP) with mean improvement of 5.5 lines (EDTRS) as best postop $(P=0.01)$ or 4.5 lines at last follow-up $(P=0.05)$ by Wilcoxon signedrank test for two paired samples.

The mean total number of retinal operations was 1.8 (range $=1-5$, median $=1$ ): nine had one operation, three had two operations, two had three operations, one had four operations, and one had five operations. Five had PVR. One patient had a history of blunt trauma to the eye. Three eyes had mild intraretinal hemorrhage lasting 1 week, moderate lasting 4 weeks, and severe lasting several months (this patient was subsequently diagnosed with Hermansky Pudlak syndrome).

\begin{tabular}{|c|c|c|c|c|c|c|c|c|}
\hline 9 & 10 & I I & 12 & 13 & 14 & 15 & 16 & 17 \\
\hline 54 & 59 & 35 & 59 & 61 & 42 & 42 & 30 & 33 \\
\hline$M$ & $\mathrm{~F}$ & $M$ & $M$ & $M$ & $M$ & $M$ & $\mathrm{~F}$ & $M$ \\
\hline C & C & $\mathrm{C}$ & $A$ & C & C & C & C & C \\
\hline OD & OD & OS & OS & OS & OD & OS & OS & ND \\
\hline CF4m & $\mathrm{HM}$ & LP & $\mathrm{HM}$ & $20 / 40$ & CF5 cm & CFIO cm & CFNF & CFNF \\
\hline Inferior & Inferior & Total & Inferior & $\begin{array}{l}\text { Supero- } \\
\text { temporal }\end{array}$ & Total & Total & Total & Superior \\
\hline On & On & On & Off & On & On & On & On & On \\
\hline $2 \mathrm{HST}$ & $\begin{array}{l}\text { HST } \\
\text { inferior }\end{array}$ & Giant tear & $\begin{array}{l}\text { HST } \\
\text { inferonasal; } \\
\text { lattice }\end{array}$ & $\begin{array}{l}\text { Dialysis } \\
\text { superior }\end{array}$ & $\begin{array}{l}2 \text { HST } \\
\text { superior; } \\
\text { lattice }\end{array}$ & $\begin{array}{l}\text { Diffuse } \\
\text { lattice }\end{array}$ & Giant tear & $\begin{array}{l}\text { HST } \\
\text { supero- } \\
\text { temporal }\end{array}$ \\
\hline No & No & CA & A & No & No & No & $\mathrm{CA}$ & No \\
\hline Moderate & No & Moderate & Moderate & Mild & Moderate & Moderate & Severe & Moderate \\
\hline No & Yes & No & Yes & No & Yes & Yes & Yes & Yes \\
\hline PPVSB & PPVSB & Phaco PPV & PPV & Laser & SBPPV & SB & SB & Laser \\
\hline 2 & I & 2 & 1 & 3 & I & 1 & 5 & 2 \\
\hline Yes & Yes & No & No & Yes & Yes & Yes & Yes & No \\
\hline Yes & Yes & Yes & Yes & No & Yes & No & Yes & Yes \\
\hline No & No & No & Yes & Yes & No & No & No & Yes \\
\hline Yes & Yes & Yes & No & No & Yes & No & Yes & No \\
\hline Yes & Yes & Yes & No & No & No & No & No & No \\
\hline Yes & Yes & No & Yes & Yes & Yes & Yes & Yes & Yes \\
\hline 72 m & $1 \mathrm{l} \mathrm{m}$ & $12 \mathrm{~m}$ & $12 \mathrm{~m}$ & $8 y$ & $8 y$ & $45 y$ & $28 y$ & $12 \mathrm{~m}$ \\
\hline CF4m & $20 / 400$ & LP & $20 / 150$ & $20 / 60$ & LP & CFIOcm & $\begin{array}{l}\text { HM from } \\
\text { severe } P C O\end{array}$ & $20 / 400$ \\
\hline $\begin{array}{l}\text { SO removal } \\
\text { then SO } \\
\text { injection }\end{array}$ & SB & $\begin{array}{l}\text { SO exchange } \\
\text { with } \\
\text { retinotomy }\end{array}$ & No & $\begin{array}{l}\text { Cryopexy then } \\
7 \text { m later SB, } \\
\text { cryopexy, gas }\end{array}$ & No & No & $\begin{array}{l}\text { Phaco with } \\
\text { implant }\end{array}$ & PPV \\
\hline
\end{tabular}


The first surgery was SB (eight eyes), four PPV(one PPV with phacoemulsification and three SB-PPV), and one laser. Silicone oil was kept in six of seven patients, for fear of redetachment or because of residual inferior detachment (three eyes), prior removal of oil had led to redetachment (one eye), and no cryopexy done to dialysis so as to not worsen PVR, so silicone oil was kept as a tamponade (one eye). The only eye that had silicone oil removal without recurrence initially had SB then PPV with oil, and removal of oil was safe. Four eyes developed glaucoma, and this was controlled by topical therapy in three eyes with silicone oil kept in the eye, and filtering in one eye (after oil removal).

Two patients were syndromic, and the ophthalmologist suspected and subsequently confirmed the diagnosis after the onset of intraocular bleeding in the operating room (Hermansky Pudlak) or deafness (albinism-deafness syndrome).

\section{Discussion}

Our findings point to the complexity of surgical management of RD in albinos. We tried to stratify the surgical difficulty according to known risk factors, such as the number and location of retinal tears, the presence of PVR, high myopia, and nystagmus (Table 1). Out of 17 eyes, 16 had identifiable tears, five had lattice degeneration, two had giant retinal tears, two had retinal dialysis, five had PVR, nine had nystagmus, and seven had high myopia. In albinism, there is difficulty in finding the retina breaks from albinotic choroid, difficulty in examining the patients by indirect ophthalmoscopy from the nystagmus and also difficulty in creating a chorioretinal adhesion. The use of wide field contact lens is helpful in dampening the nystagmus and examination of the peripheral retina. Drainage of subretinal fluid with a SB gave a good result. Vitrectomy with silicone oil fill was used successfully in more complex cases, with the need to keep the oil for a protracted time for fear of redetachment or because $\mathrm{RD}$ recurred after oil removal.

It is still unclear if retinal pigment epithelium (RPE) cells in albinos are less reactive than normal RPE cells. The use of cryotherapy enhances intravitreal dispersion of RPE cells. ${ }^{6}$ The exact role of melanin granules in causing a good chorioretinal scar is unclear. ${ }^{7,8}$ Melanin granules are involved in several functions: 1) a decrease in oxidative stress; 2) protection against lipofuscin damage; and 3) storage of zinc that is essential for superoxide dismutase function. It was stated that there is less PVR in albino RD. ${ }^{1}$ The current multiracial case series may not support that previous conclusion. The presence of PVR was noted in some of our patients: 1) late presentation of $\mathrm{RD} ; 2$ ) the need for high energy laser or cryotherapy may also trigger PVR; and 3 ) the need for several surgeries and the low success rate with one operation.

Albinos may have a higher incidence of posterior vitreous detachment(PVD) from nystagmus-induced early-onset PVD. ${ }^{9}$ Albinos with more severe nystagmus may have more difficulty in keeping the retina attached, as rapid saccadic eye movements generate continuous motions in the liquid vitreous capable of worsening a detached retina or reopening a poorly sealed tear. ${ }^{9-19}$ Saccadic eye movements are considered by some researchers as a crucial factor in preventing retinal reattachment and hence, such eyes are to be treated in special ways. Experimental models ${ }^{13,15,16}$ and vitreous imaging in vivo ${ }^{14}$ demonstrated the detrimental effect of fast nystagmus in eyes with partial PVD and traction on horseshoe tears. A majority of albinos have either vigorous spontaneous nystagmus (pendular unidirectional or bidirectional jerk) or vigorous unidirectional jerk nystagmus that reverses in direction spontaneously. ${ }^{20,21}$ On the other hand, a well-known method to decrease a RD is bilateral eye patch. ${ }^{18,22}$ By electro-oculography, bilateral patching resulted in a marked decrease in both amplitude and frequency of ocular movement. ${ }^{23}$ Immobilization of the eye by using fixation sutures under the inferior recti and medial recti can flatten the retina in eyes with $\mathrm{RD}$ in a large proportion of patients. ${ }^{10-12,19,24}$

When SB is done, there is a need to flatten the retina completely because the fast nystagmus in patients with albinism can redetach the retina by shifting residual subretinal fluid toward the site of the tear. ${ }^{25-28}$ Also in complex $\mathrm{RD}$ with inferior retinal tears, the standard of care would include PPV with maximal regular silicone oil fill, or PPV with SB and silicone oil fill, or PPV with heavy density silicone oil.

Several syndromes have been associated with albinism, and their recognition is important in the prevention or management of potential ocular complications..$^{29,30}$ HermanskyPudlak syndrome is a rare autosomal recessive triad of oculocutaneous albinism, bleeding problems due to platelet storage pool defect, and lysosomal accumulation of ceroid lipofuscin. ${ }^{30}$ We recognized this syndrome postoperatively in one of our patients who developed an unexpected intraocular bleed. Avoiding ocular hypotension and use of desmopressin acetate could have prevented this complication, knowing that our patient had a brother with a known bleeding tendency. Chédiak-Higashi syndrome is also a rare autosomal recessive disorder of neutrophils (large lysosome vesicles) with resultant poor bactericidal function and susceptibility to 


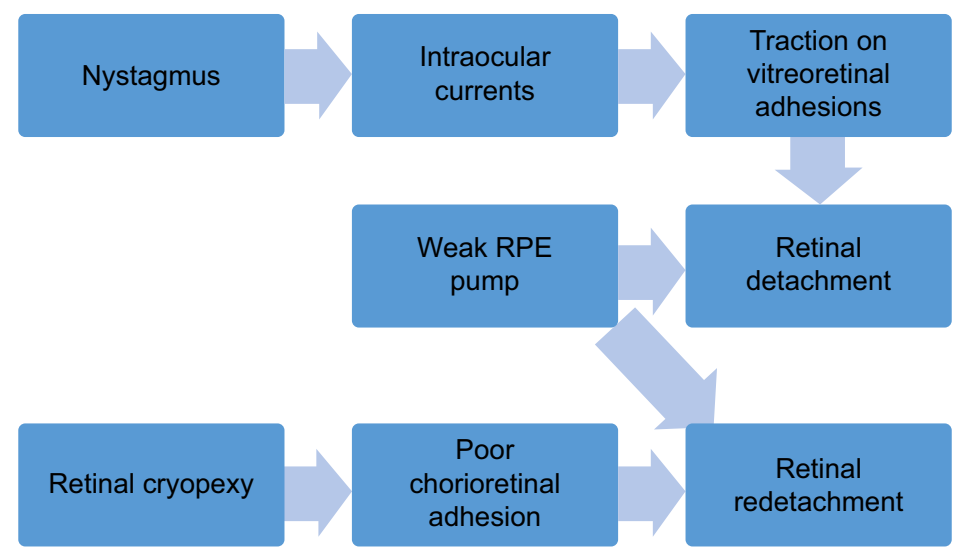

Figure I Flow chart of the pathophysiology of retinal detachment in albinos. Abbreviation: RPE, retinal pigment epithelium.

repeated infections. ${ }^{30}$ Ocular albinism-deafness syndrome is characterized by a rare form of sex-linked congenital sensorineural hearing loss. ${ }^{31}$

Limitations of the current study include its retrospective nature, the short follow-up in several cases, and the variability in the initial surgical approach. In summary, endolaser or slit-lamp laser photocoagulation may be inefficient, and are often accompanied by ocular hemorrhage from use of high energy in eyes with albinism and RD. Cryopexy seems to be the preferred technique to induce chorioretinal adhesion, despite the risk of exacerbating PVR. Both SB and PPV were efficacious and appear to be good surgical techniques for use in this patient population. SB is a successful technique in simple RD. Pars plana vitrectomy is indicated in more complex $\mathrm{RD}$, and there is a high need to use silicone oil tamponade and keep the oil tamponade for a long time. Inferior RD may recur, despite the presence of silicone oil in eyes with albinism. Silicone oil removal in eyes with albinism appears to lead to a high rate of RD. ${ }^{32}$ Attention to comorbidities can help to decrease the occurrence of surgical complications. In conclusion, the combination of vitreoretinal traction, intraocular currents, and retinal tear can lead to $\mathrm{RD}$, unless counteracted by the pigment epithelium. Achieving a good chorioretinal scar ablates the effects of intraocular currents. In albinism, intraocular currents are maximized, the chorioretinal scar is suboptimal, and the RPE pump may be deficient or weak (Figure 1). Hence, the need to seal tears by cryotherapy and SB with or without vitrectomy and long-term silicone oil tamponade. Despite the limitations of a small retrospective case series, the current data favor a more aggressive approach in albino $\mathrm{RD}$, hence maximal surgery ( $\mathrm{SB}$, vitrectomy, cryopexy) seems preferable over minimal surgery (pneumatic retinopexy, laser).

\section{Disclosure}

The authors report no conflicts of interest in this work.

\section{References}

1. Sinha MK, Chhablani J, Shah BS, Narayanan R, Jalali S. Surgical challenges and outcomes of rhegmatogenous retinal detachment in albinism. Eye. 2016;30:422-425.

2. Yang JW, Lee SJ, Kang SB, Park YH. A case of retinal detachment surgery in albinism patient. J Korean Ophthalmol Soc. 2008; 49:840-844.

3. Hiroshi M, Hiroyuki M. A case of ocular albinism with rhegmatogenous retinal detachment. Jap Rev Clin Ophthalmol. 1999;93:861-864.

4. Mal W, Zafar S, Siddiqi S, Rizvi SF. Retinal detachment surgery in oculocutaneous albino patient. Pak J Ophthalmol. 2013;29:235-237.

5. Machemer R, Aaberg TM, Freeman HM, Irvine AR, Lean JS, Michels RM An updated classification of retinal detachment with proliferative vitreoretinopathy. Am J Ophthalmol. 1991;112:159-165.

6. Campochiaro PA, Kaden IH, Vidaurri-Leal J, Glaser BM. Cryotherapy enhances intravitreal dispersion of variable pigment epithelial cells. Arch Ophthalmol. 1985;103:434-436.

7. Peters S, Schraermeyer U. Charakteristika und funktionen des melanins im retinalen pigmentepithel [Characteristics and functions of melanin in retinal pigment epithelium]. Ophthalmologe. 2001;98:1181-1185. German.

8. Schütze C, Ritter M, Blum R, et al. Retinal pigment epithelium findings in patients with albinism using wide-field polarization-sensitive optical coherence tomography. Retina. 2014;34:2208-2217.

9. Bonfiglio A, Lagazzo A, Repetto R, Stocchino A. An experimental model of vitreous motion induced by eye rotations. Eye Vis (Lond). 2015;2:10.

10. Algvere P, Rosengren B. Immobilization of the eye. Evaluation of a new method in retinal detachment surgery. Acta Ophthalmol. 1977;55: 303-316.

11. Chen CY, Chen SN, Lin SM, Ho CL. Reduction of subretinal fluid after preoperative immobilization of the eyes with rhegmatogenous retinal detachment. Chang Gung Med J. 2001;24:799-804.

12. Dorrepaal SJ, Gale J. Using patient positioning to promote resorption of subretinal fluid in rhegmatogenous retinal detachment before pneumatic retinopexy. Retina. 2014;34:477-482.

13. Repetto R, Tatone A, Testa A, Colangeli E. Traction on the retina induced by saccadic eye movements in the presence of posterior vitreous detachment. Biomech Model Mechanobiol. 2011;10:191-202.

14. Piccirelli M, Bergamin O, Landau K, Boesiger P, Luechinger R. Vitreous deformation during eye movement. NMR Biomed. 2012;25:59-66.

15. David T, Smye S, Dabbs T, James T. A model for the fluid motion of vitreous humour of the human eye during saccadic movement. Phys Med Biol. 1998;43:1385-1399. 
16. Meskauskas J, Repetto R, Siggers JH. Shape change of the vitreous chamber influences retinal detachment and reattachment processes: is mechanical stress during eye rotations a factor? Invest Ophthalmol Vis Sci. 2012;53:6271-6281.

17. Rosengren B, Oesterlin S. Hydrodynamic events in the vitreous space accompanying eye movements. Significance for the pathogenesis of retinal detachment. Ophthalmologica. 1976;173:513-524.

18. Foster WJ. Bilateral patching in retinal detachment: fluid mechanics and retinal "settling”. Invest Ophthalmol Vis Sci. 2011;52:5437-5440.

19. Algvere P, Rosengren B. Active immobilization of the eye in the treatment of retinal detachment. Mod Probl Ophthalmol. 1977;18: 286-291.

20. Collewijn H, Apkarian P, Spekreijse H. The oculomotor behaviour of human albinos. Brain. 1985;108:1-28.

21. Hertle RW. Albinism: particular attention to the ocular motor system. Middle East Afr J Ophthalmol. 2013;20:248-255.

22. Lincoff H, Stopa M, Kreissig I. Ambulatory binocular occlusion. Retina. 2004;24:246-253.

23. Adams GL, Yee RD, Hahn PM, Pearlman JT. Effect of binocular and monocular patching on eye movements. Arch Ophthalmol. 1973;90: 117-120.

24. Arruga A. Posterior fixation of recti in nystagmus with retinal detachment. Mod Probl Ophthalmol. 1975;15:304-306.
25. Machemer R. The importance of fluid absorption, traction, intraocular currents, and chorioretinal scars in the therapy of rhegmatogenous retinal detachments. XLI Edward Jackson memorial lecture. Am J Ophthalmol. 1984;98:681-693.

26. Angunawela RI, Azarbadegan A, Aylward GW, Eames I. Intraocular fluid dynamics and retinal shear stress after vitrectomy and gas tamponade. Invest Ophthalmol Vis Sci. 2011;52:7046-7051.

27. Kuhn F, Aylward B. Rhegmatogenous retinal detachment: a reappraisal of its pathophysiology and treatment. Ophthalmic Res. 2014; 51:15-31.

28. Clemens S, Kroll P, Stein E, Wagner W, Wriggers P. Experimental studies on the disappearance of subretinal fluid after episcleral buckling procedures without drainage. Graefes Arch Clin Exp Ophthalmol. 1987; 225:16-18.

29. Kinnear PE, Jay B, Witkop CJ Jr. Albinism. Surv Ophthalmol. 1985;30: 75-101.

30. McHam ML, Fulton A. Albinism. Int Ophthalmol Clin. 1992;32: 185-200.

31. Margolis E. A new hereditary syndrome-sex-linked deaf-mutism associated with total albinism. Acta Genet Statist Med. 1962;12:12-19.

32. Yilmaz T, Güler M. The role of nystagmus in silicone oil emulsification after pars plana vitrectomy and silicone oil injection for complex retinal detachment. Eur J Ophthalmol. 2008;18:150-154.
Clinical Ophthalmology

\section{Publish your work in this journal}

Clinical Ophthalmology is an international, peer-reviewed journal covering all subspecialties within ophthalmology. Key topics include: Optometry; Visual science; Pharmacology and drug therapy in eye diseases; Basic Sciences; Primary and Secondary eye care; Patient Safety and Quality of Care Improvements. This journal is indexed on

\section{Dovepress}

PubMed Central and CAS, and is the official journal of The Society of Clinical Ophthalmology (SCO). The manuscript management system is completely online and includes a very quick and fair peer-review system, which is all easy to use. Visit http://www.dovepress.com/ testimonials.php to read real quotes from published authors. 